\title{
ABORDAGEM HÍBRIDA DE GERENCIAMENTO DE PROJETOS DE NOVOS PRODUTOS: O CASO DA DISCIPLINA DE CURSO DE GRADUAÇÃO
}

Laíssa Nogueira Rêgo (laissa.nr@gmail.com) - Departamento de Engenharia de Produção, Universidade Federal do Rio Grande do Norte (UFRN).

Mario Orestes Aguirre González (mariooagonzalez@gmail.com) - Departamento de Engenharia de Produção, Universidade Federal do Rio Grande do Norte (UFRN).

Técia de Lima Silva (tecia-lima@hotmail.com) - Departamento de Engenharia de Produção, Universidade Federal do Rio Grande do Norte (UFRN).

\section{RESUMO}

O desenvolvimento de novos produtos é cada vez mais relevante para as empresas devido a crescente diversidade de itens e a maior exigência dos clientes por novidades. Baseando-se nisso, a disciplina de Laboratório de Engenharia do Produto ofertada pela Universidade Federal do Rio Grande do Norte (UFRN) é fundamentada em técnicas que potencializam a criatividade para a inovação. Dessarte, um novo produto parte inicialmente de um projeto de inovação e, portanto, o método escolhido para gerenciá-lo interfere diretamente na possibilidade desse ser capaz de obter entregas competitivas em menos tempo. Diante disso, o artigo objetiva propor um modelo de gerenciamento de projetos de desenvolvimento de novos produtos. Assim, foi realizada uma revisão da literatura nas áreas de estudo e uma pesquisa qualitativa com os discentes da disciplina. Para tanto, desenvolveu-se um modelo conceitual que foi validado através de uma sessão de focus group com a participação de especialistas em gerenciamento de projetos. Como resultado é apresentado um modelo híbrido para gerenciamento de projetos de desenvolvimento de novos produtos com foco em curto prazo, com recursos financeiros escassos e equipes que não possuem disponibilidade integral.

Palavras chave: Gerenciamento de Projetos de Desenvolvimento de Novos Produtos; Projetos de inovação; Abordagem Híbrida 


\section{INTRODUÇÃO}

O desenvolvimento de produtos é um processo cada vez mais relevante para a competitividade das empresas. No cenário atual do mercado há maiores possibilidades de escolhas de produtos, já que com o desenvolvimento das tecnologias de informação os clientes estão mais informados e o mercado está mais globalizado (ROZENFELD et al., 2006).

É a partir deste processo que a empresa tem a possibilidade de criar, em menos tempo, novos produtos mais competitivos para atender à dinamicidade e a constante evolução do mercado e da tecnologia (ROZENFELD et al., 2006). Todavia, um produto desenvolvido parte inicialmente de um Projeto de Inovação (PI).

Tendo isso em vista, os métodos e abordagens escolhidas para gerenciar um PI afetam diretamente nas chances de sucesso ou de falha do mesmo. Isso porque, devido aos altos riscos envolvidos e a menor confiança nos resultados, espera-se que a sua gestão seja diferenciada em relação a projetos não inovadores (DÉAK, 2009).

Contudo, embora haja restrições de recursos humanos e financeiros, para manter a empresa competitiva é necessário atender as necessidades e a dinamicidade do mercado. Isto é, PIs relacionados ao desenvolvimento do produto exigem rapidez nos resultados para possibilitar o acompanhamento da evolução contínua do mercado e das tecnologias (ROZENFELD et al., 2006).

Diante da importância da inovação no mercado, a UFRN tem em suas estratégias a promoção da inovação como objetivo institucional (UFRN, 2017). Alinhado a isso, a disciplina de Laboratório de Engenharia do Produto tem sua ementa fundamentada em técnicas e exercícios que potencializam a criatividade para a inovação aplicadas no desenvolvimento de novos produtos (GONZÁLEZ, 2019).

Semelhante às empresas, os discentes desta disciplina não possuem dedicação exclusiva ao projeto por terem outras atividades acadêmicas em suas rotinas, além de restrições relacionadas aos recursos financeiros e exigências de entregas respeitando um curto prazo para desenvolverem os produtos.

Destarte, o presente artigo objetiva propor um modelo de gerenciamento de projetos para desenvolvimento de novos produtos que responda a seguinte questão: como gerenciar projetos de desenvolvimento de novos produtos quando seus integrantes não possuem disponibilidade integral ao projeto, os recursos financeiros são escassos e há uma exigibilidade de cumprimento em curto prazo? 


\section{FUNDAMENTAÇÃO TEÓRICA}

\subsection{Gestão de Projetos de Inovação}

A inovação está presente, mesmo que minimamente, em quase todos os projetos. Todo projeto agrega algo novo e possui riscos envolvidos (DÉAK, 2009). Entretanto, ao explorar novas áreas, como é caso de projetos inovadores (PI), a incerteza é um fator ainda mais ativo.

Assim, os projetos inovadores enfrentam frequentes mudanças de escopo, ciclos de vida extensos e, geralmente, incertos, conflitos de interesse entre a equipe, imprevisibilidade do tempo e da criatividade, além de dificuldades de captar recursos. Logo, espera-se que a sua gestão, como também a utilização de algumas soluções e ferramentas, seja diferenciada dos demais tipos de projetos (DÉAK, 2009).

Cada projeto em si é único e, assim, possui necessidades distintas exigindo abordagens de gerenciamento diferentes para atendê-lo (BIANCHI, 2017; EDER et al, 2014). Neste sentido, existem duas principais abordagens da Gestão de Projetos (GP): tradicional (plandriven) e ágil.

A abordagem tradicional, também conhecida plan-driven, tem como propriedade a linearidade das fases do projeto, em que a definição de todos os requisitos dos projetos é feita na fase inicial (SILVA, 2018; BIANCHI, 2017). Outrossim, as características principais da abordagem tradicional estão voltadas à previsibilidade, estabilidade e alta garantia do projeto (BIANCHI, 2017; BOEHM; TURNER, 2003).

Esta abordagem tem como principal referência o guia PMBOK® (Project Management Body of Knowledge). Nele, são detalhados processos, habilidades, ferramentas e técnicas (BARBALHO; CASTELLANI, 2014); incluindo tanto práticas tradicionais comprovadas e amplamente aplicadas na GP, como práticas inovadoras, já que o guia PMBOK® está em constante evolução (PMI, 2017).

Apesar da plan-driven funcionar para o gerenciamento de vários tipos de projetos, o seu escopo engessado fez com que diversos profissionais questionassem sua aplicação no desenvolvimento de softwares. Dessa forma, foi criada a abordagem ágil de projetos.

A Gestão Ágil de Projetos (GAP) é um processo mais simplificado, flexível e com maior interação da equipe com o cliente final (AMARAL; CONFORTO, 2014).

Desse modo, os métodos ágeis se caracterizam por defender que as entregas parciais sejam efetuadas em um curto período de tempo, denominado de iteração, bem como por prezar 
pelo envolvimento e pela participação do cliente final do projeto, e pela simplicidade na documentação do projeto (BIANCHI, 2017). A abordagem ágil possui diversos métodos, entre os mais famosos está o scrum.

O scrum é definido como um método, no qual as pessoas podem tratar "problemas adaptativos complexos, enquanto entregam produtiva e criativamente produtos do mais alto valor possível" (SCHWABER; SUTHERLAND, 2017, p. 3). Este método é baseado em processos empíricos, que defendem que o conhecimento é gerado a partir da experiência e que as tomadas de decisões devem ser feitas baseadas no que se conhece (SCHWABER; SUTHERLAND, 2017).

Sem embargo essas duas abordagens tenham estruturas divergentes e sejam mais aplicáveis em tipos de projetos diferentes, muitas vezes elas são utilizadas de forma adaptada, tendo algumas práticas e ferramentas combinadas entre si, o que é conhecido como gestão de projetos híbrida (BIANCHI, 2017).

\subsection{Desenvolvimento de Produtos}

O desenvolvimento de produtos (DP) consiste na realização de um conjunto de atividades que visa alcançar às especificações de projeto de um produto e de seu processo produtivo, partindo das necessidades do mercado e das competências e restrições tecnológicas, considerando as estratégias competitivas da empresa e do produto (ROZENFELD et al., 2006).

O DP baseia-se em fluxo de atividades e de informações que compreende tanto as ligações entre as áreas da empresa quanto entre a empresa, o mercado e os stakeholders (ROZENFELD et al., 2006). Porém, esse processo ainda é abordado numa visão tradicional que o encara como "um conjunto de informações sobre as especificações de um produto, sobre como produzi-lo e sua disponibilização para a manufatura" (ROZENFELD et al., 2006, p.10), mas essa visão entra em confronto com outras abordagens que integram as áreas empresariais e os outros elos da cadeia de valor no DP (Figura 1). 


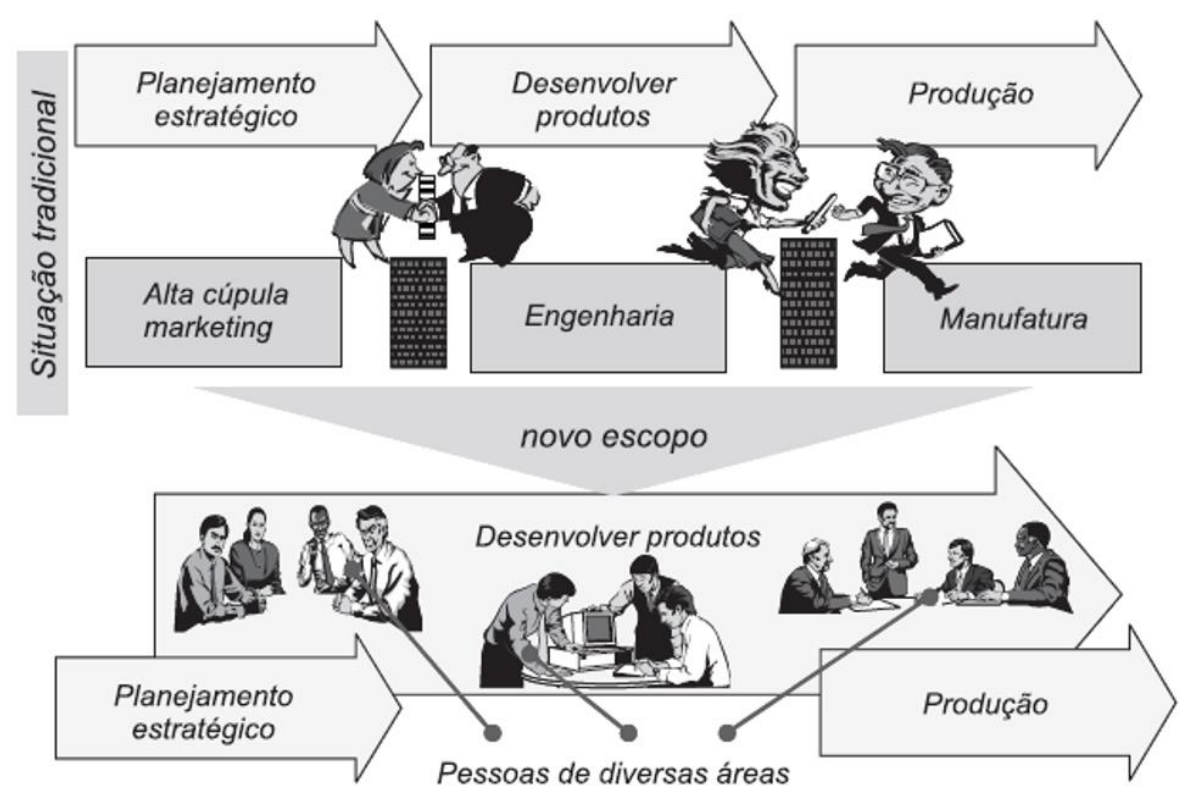

FIGURA 1- Escopos do DP

FONTE: Rozenfeld et al. (2006).

Este novo escopo do DP defende a criação de um ambiente mais interativo e de compartilhamento de informações, em que os stakeholders são envolvidos no processo. Essa visão é justificada para melhorar e reformular o produto desenvolvido, e evitar a ocorrência de erros semelhantes nos processos de desenvolvimento futuros (ROZENFELD et al., 2006).

Toda empresa que traz um novo produto ao mercado usa alguma forma de modelo de desenvolvimento de produto, Rozenfeld et al. (2006) adota o modelo ilustrado na Figura 2.

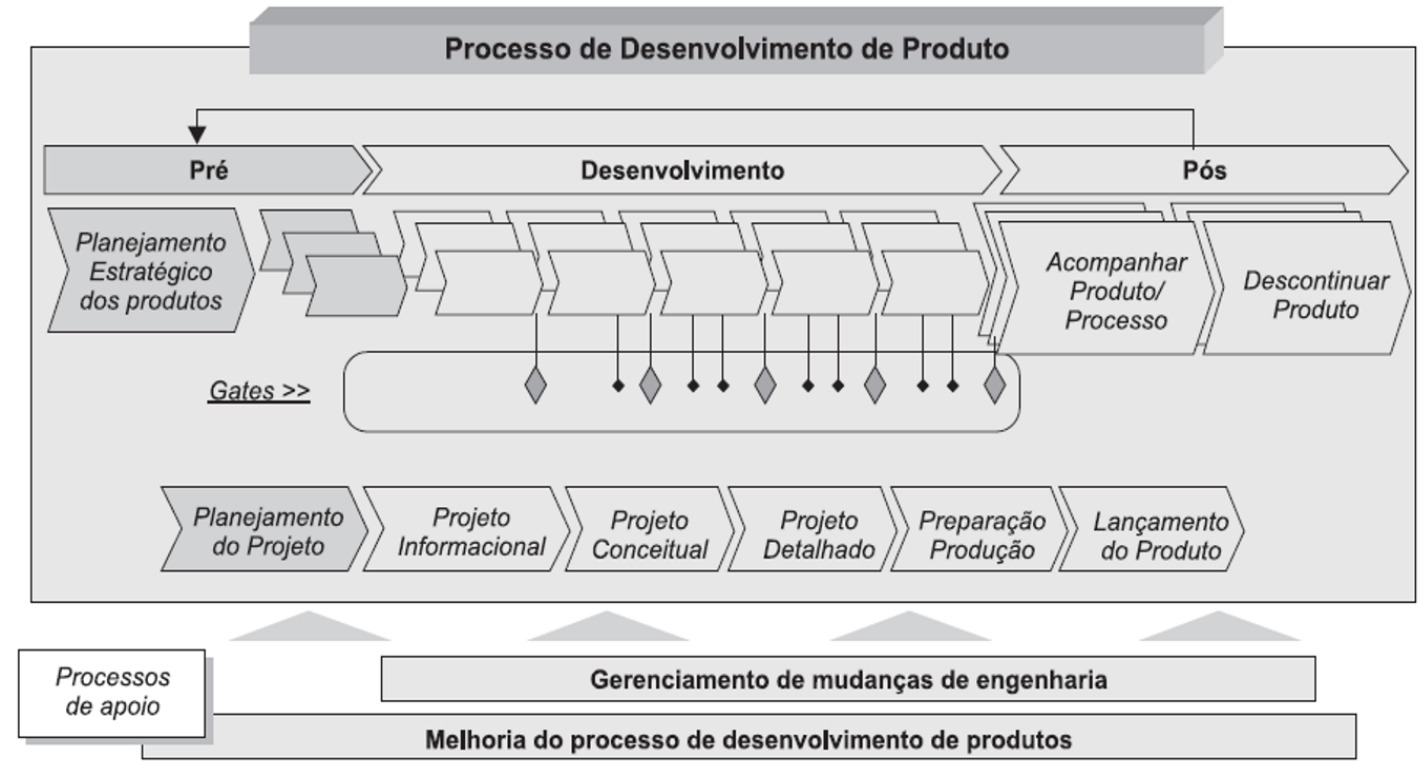

FIGURA 2 - Fases do DP

FONTE: Rozenfeld et al. (2006). 
A etapa de desenvolvimento do produto é realizada a partir de fases sequenciais dependentes umas das outras e, portanto, é relevante ressaltar que, neste modelo, uma determinação inapropriada no projeto informacional poderá causar uma série de decisões em cascata que resultarão em uma solução indesejada (ROZENFELD et al., 2006).

\subsection{Características da Gestão de Projetos no Desenvolvimento de Novos Produtos}

As características para a GP de desenvolvimento de novos produtos estão resumidas na Figura 3.

\begin{tabular}{|c|c|}
\hline Aspectos & Características \\
\hline Escopo & Flexível e adaptável \\
\hline Comunicação & Rápida e eficaz \\
\hline Equipe & Motivada e com as expectativas sobre produto alinhadas \\
\hline Cliente & Próximo do processo de desenvolvimento \\
\hline
\end{tabular}

FIGURA 3 - Gestão de Projetos de desenvolvimento de novos produtos

FONTE: Elaboração própria (2019).

\section{METODOLOGIA}

O procedimento desta pesquisa contemplou quatro etapas: revisão da literatura, observação, modelagem e validação do modelo conceitual.

A revisão da literatura considerou a busca do conhecimento nas áreas de gestão de projetos de inovação, abordagens de inovação de produtos e de desenvolvimento de novos produtos. Para tanto, utilizou-se a base de dados Periódicos CAPES na busca pelos artigos, além de dissertações, monografias, livros, sites e referências dos artigos seguindo o processo ilustrado na Figura 5. 


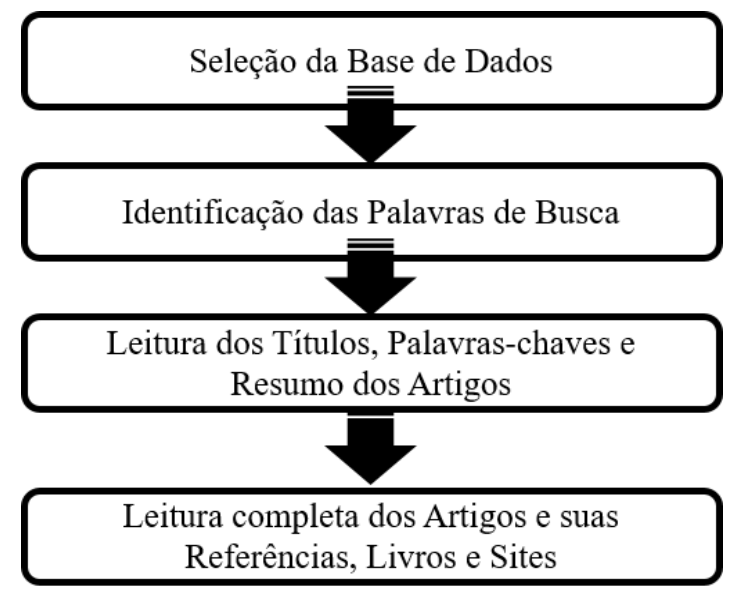

FIGURA 5- Revisão da literatura

FONTE: Elaboração própria (2019).

Tendo em vista a fase de observação foi acompanhado, presencialmente, o desenvolvimento de novos produtos por três equipes da disciplina de Laboratório de Engenharia de Produto da UFRN, identificando as dificuldades da equipe na gestão e no desenvolvimento de cada projeto a partir de uma pesquisa qualitativa.

Já na pesquisa qualitativa, foram levantadas questões relacionadas a prazos, conhecimentos técnicos, restrição orçamentária e de recursos humanos, tempo de disponibilidade para o projeto e papel do coordenador do projeto.

Os conhecimentos teóricos obtidos possibilitaram sintetizar os elementos da gestão de projetos de desenvolvimento de novos produtos e, juntamente com as dificuldades elencadas pelas equipes na etapa de observação, foi possível elaborar o modelo conceitual para a gestão de projetos para o desenvolvimento de novos produtos. Para validar este modelo foi utilizada a técnica de focus group.

Esta técnica consiste na coleta de dados qualitativos através da interação de um grupo a respeito de um tópico determinado pelo pesquisador (MORGAN, 1997). Deve ser realizada com um grupo formado por indivíduos com características comuns e um moderador, que exerce uma função de líder (GALEGO; GOMES, 2005). O focus group teve sua aplicação conforme fluxo da Figura 6.

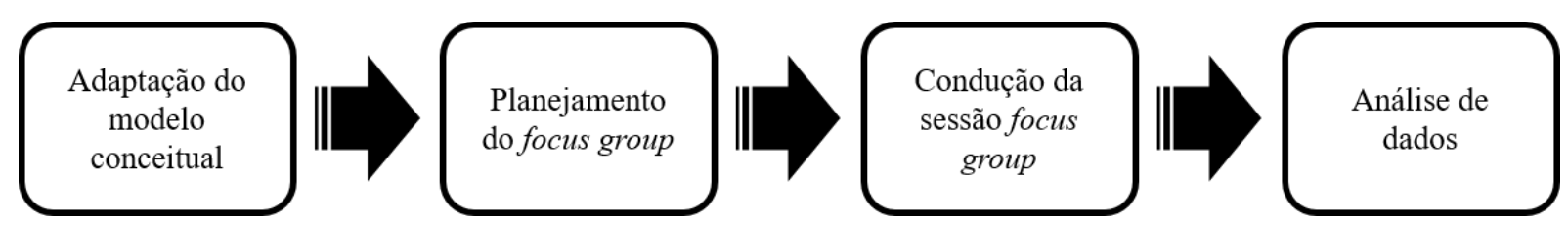

FIGURA 6- Validação do modelo

FONTE: Elaboração própria (2019). 


\section{ESTUDO DE CASO}

\subsection{Laboratório De Engenharia Do Produto}

A disciplina de Laboratório de Engenharia do Produto tem sua ementa fundamentada em técnicas que potencializam a criatividade para a inovação aplicadas no desenvolvimento de novos produtos.

Para isso, ao decorrer da disciplina os alunos desenvolveram um produto totalmente novo, a partir das entregas parciais e apresentações (Figura 7).

\begin{tabular}{|l|l|}
\hline $1^{\text {a }}$ Entrega & Ideia de um novo produto \\
\hline $2^{\text {a }}$ Entrega & Planejamento do projeto de um novo produto \\
\hline $3^{\text {a }}$ Entrega & Projeto informacional \\
\hline $4^{\text {a }}$ Entrega & Projeto conceitual e protótipo virtual \\
\hline $5^{\text {a }}$ Entrega & Projeto detalhado e protótipo virtual detalhado \\
\hline $6^{\text {a }}$ Entrega & Protótipo físico do novo produto \\
\hline
\end{tabular}

FIGURA - 7 Entregas parciais

FONTE: Adaptado de González (2019).

Para desenvolver o produto, os discentes foram divididos em três equipes multidisciplinares de cinco integrantes, com alunos de diferentes cursos. A coordenação de cada projeto foi assumida por um dos alunos como uma função rotativa, ou seja, a cada entrega parcial um componente assumia a liderança.

A cada entrega parcial, os alunos apresentavam o que foi desenvolvido e ouviam feedbacks das outras equipes e do professor, podendo implementar melhorias ao decorrer do desenvolvimento. Ao final, cada equipe entregou um protótipo do produto para ser exposto em uma mostra e avaliado.

\section{PROPOSTA DO MODELO}

O modelo tem por objetivo gerenciar de projetos voltados ao desenvolvimento de novos produtos, que devem ser realizados em um curto prazo, com equipes que não possuem dedicação integral ao projeto e com recursos financeiros escassos.

Para atender o objetivo proposto, o modelo segue uma abordagem híbrida, que se utiliza do scrum e do PMBOK®. Ademais, ele também possui as premissas que: as relações 
entre o cliente e a equipe sejam estreitas (reduzindo incertezas existentes) e que projetos de curto prazo são aqueles com duração de até seis meses.

O modelo divide o projeto em dois momentos:

- Planejamento tático: define diretrizes essenciais sobre gerenciamento do projeto e conceitua de forma geral o produto para que seja possível o seu desenvolvimento. Esta fase possui um fluxo linear com etapas bem definidas, semelhante ao proposto pelo PMBOK® (Figura 8).

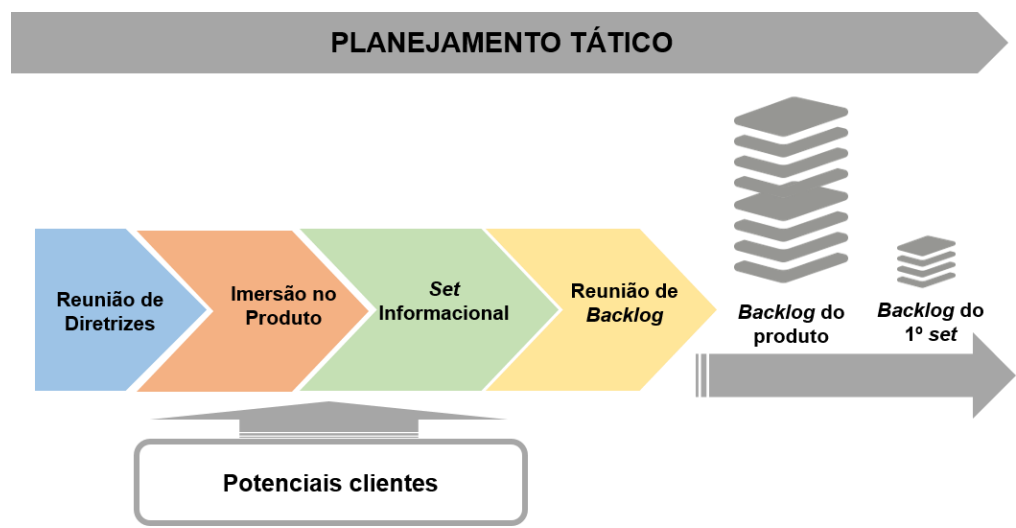

FIGURA 8- Planejamento Tático

FONTE: Elaboração própria (2019).

- Sets: fase que tem seu funcionamento baseado em um sistema cíclico semelhante ao de sprints proposto pelo scrum (Figura 9). Em um set existem etapas de planejamento voltadas ao desenvolvimento do produto, execução e validação. 


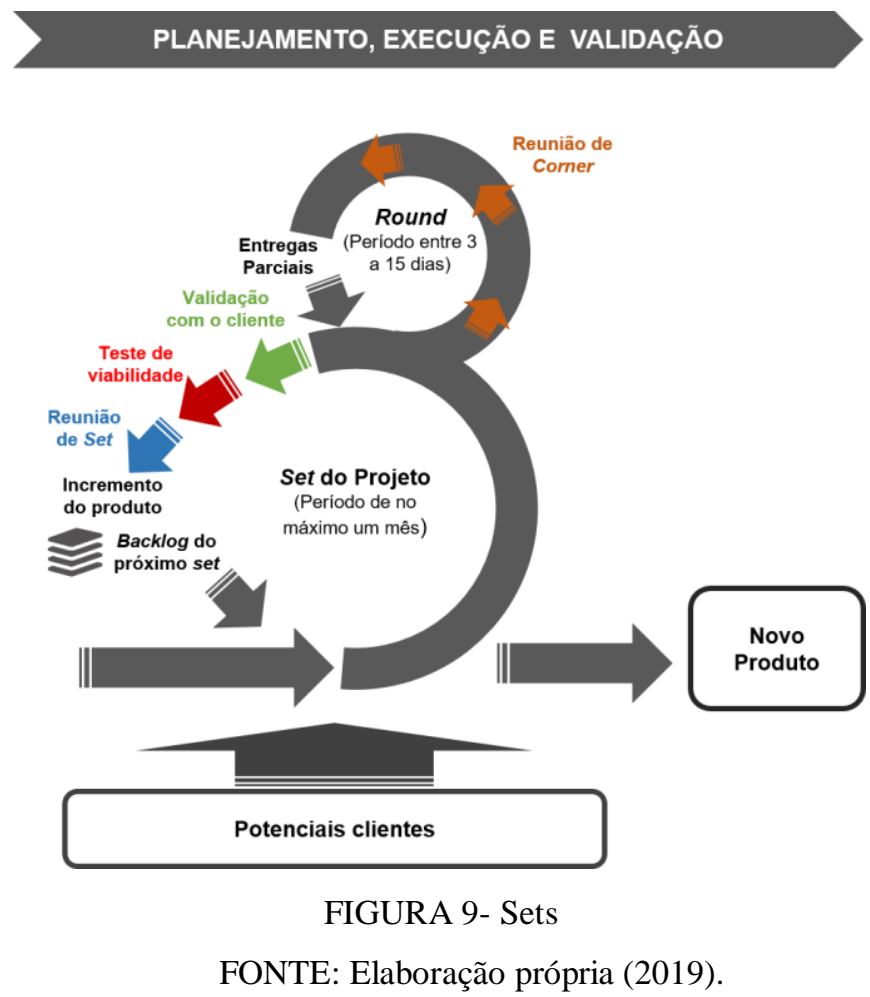

\subsection{Planejamento Tático}

O planejamento tático consiste na primeira fase do projeto, ela é dividida em quatro etapas principais: reunião de diretrizes, imersão no produto, set informacional e reunião de backlog.

Para registrar as decisões desta fase sem que haja produções excessivas de documentações e permitir a gestão visual do projeto, foi desenvolvida uma ferramenta chamada de plano tático (Figura 10), que será elaborado ao decorrer desta fase, mas poderá ser modificado ao longo do projeto. 


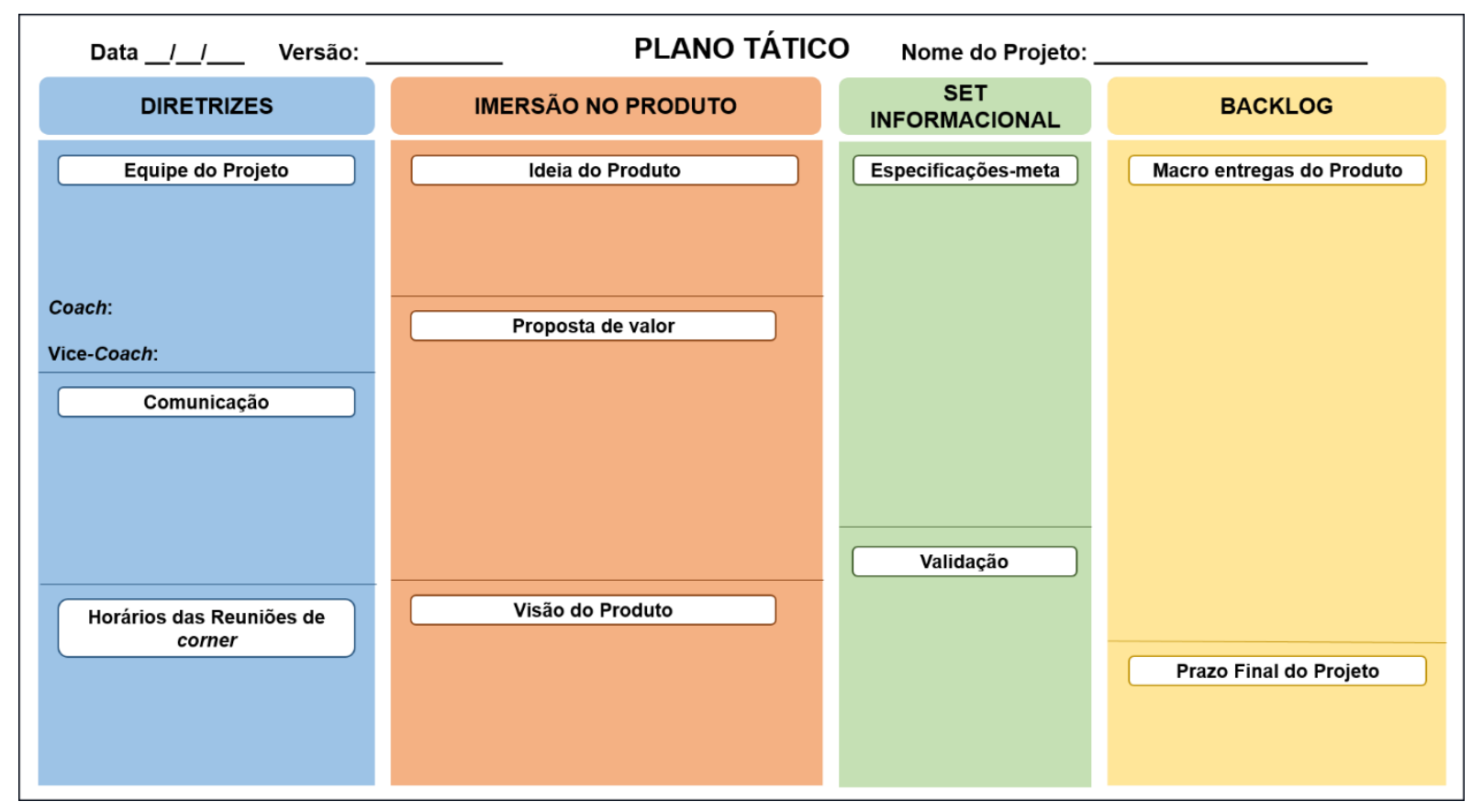

FIGURA 10- Plano Tático

FONTE: Elaboração própria (2019).

\subsubsection{Reunião de Diretrizes}

Na reunião de diretrizes é estruturada e formalizada a equipe do projeto. Esta equipe deverá ser multidisciplinar e com poucos membros, visto que há uma maior dificuldade em conciliar horários e rotinas de trabalho em equipes grandes onde os membros não têm dedicação integral ao projeto.

É nesta etapa que o papel dos membros da equipe é determinado, devendo identificar os horários disponíveis para o projeto e definir os dias que acontecerão as reuniões de corner. Além disso, na reunião de diretrizes é formalizada comunicação entre os membros e como será realizado o acompanhamento do projeto mantendo a sua transparência. Ao final da reunião, as decisões tomadas devem ser registradas no plano tático.

\subsubsection{Imersão no Produto}

A segunda etapa do planejamento tático consiste na imersão do produto. Nela, a equipe desenvolve e constrói a ideia do produto, que deve ser colaborativa, na qual, os membros depositam suas expectativas e desenvolvem uma ideia final juntos. Isso é fundamental para que todos tenham a sensação de pertencimento ao projeto, se identifiquem com o novo produto e fiquem motivados a desenvolvê-lo. 
Após a concepção da ideia, é construída a proposta de valor do produto de forma conjunta com o seu potencial cliente, consumidor ou usuário. Essa proposta objetiva validar a ideia do produto e deve responder quatro pontos: qual o valor que o produto entrega para o cliente; quais são os problemas que o produto está solucionando; quais são as necessidades dos clientes que o produto satisfaz; e, o que torna o produto original e diferente.

Com a construção da proposta de valor, é formalizada a visão do produto, isto é, a razão de existência do produto, que deverá nortear as decisões no decorrer do projeto, como a priorização de incrementos e implementação de melhorias. Ao final da imersão, as decisões devem ser registradas no plano tático.

\subsubsection{Set Informacional}

O set informacional é a terceira etapa do planejamento tático. A equipe de projeto deverá definir os requisitos dos clientes e do produto, a fim de entregar as especificações-meta do produto.

Esta etapa deverá ser construída de forma colaborativa com potenciais clientes, com intuito de minimizar as incertezas existentes no início do projeto e monitorar a viabilidade do produto.

Outrossim, serão definidas as estratégias utilizadas para a validação dos incrementos do produto com o cliente ao final de cada set do projeto. Todas as decisões tomadas nesta etapa devem ser documentadas no plano tático.

\subsubsection{Reunião de Backlog}

Nesta reunião será definido o backlog do produto, ou seja, quais serão os incrementos viáveis para o produto que serão entregues. Nela também será delimitado o prazo de entrega final do projeto e a quantidade de sets que deverá ter. Essas informações devem ser documentadas no plano tático. Além de que, esta reunião também definirá quantos rounds terão o primeiro set, a duração dos rounds, qual será o seu prazo limite e quais são as entregas parciais.

\subsection{Sets}

A fase dos sets determinará todo restante do projeto. Os sets consistem em um conjunto de pequenas iterações do projeto, chamadas de rounds. Cada set do projeto objetiva 
entregar uma parte viável do produto. E, conforme exposto, a quantidade de sets que um projeto deve ter é definida na fase de planejamento tático e orientada pelo backlog do produto.

Um set poderá ter quantidades de rounds diferentes de outro set, e podem ter tempos de duração distintos dependendo da complexidade da entrega final. Todavia, apesar de um set não possuir uma duração determinada, não deve este superar o período de um mês para ser finalizado.

\subsubsection{Validação com o cliente}

A validação com o cliente ocorre no final de cada set e será coordenada pelo coach, função que será detalhada posteriormente. A estratégia para a execução desta etapa é determinada pela própria equipe; ela objetiva apresentar o incremento do produto desenvolvido no respectivo set, para que os clientes validem e proponham melhorias.

\subsubsection{Teste de viabilidade}

O teste de viabilidade acontece após a validação com o cliente. Ele deve ser realizado pelo coach e objetiva verificar se, com as melhorias propostas pelos potenciais clientes, o desenvolvimento do produto ainda é viável. Portanto, esse teste deverá responder se o produto é tecnicamente e financeiramente viável.

\subsubsection{Reunião de set}

Após o teste de viabilidade, acontecerá a reunião de set com a participação de toda equipe. Esta reunião é responsável por formalizar a entrega do incremento do produto, apresentar as melhorias sugeridas pelos clientes durante a validação, comunicar o teste de viabilidade realizado, definir as mudanças que serão implementadas, atualizar o backlog do produto e o plano tático do projeto.

Nesta reunião também é definido quantos rounds terão o próximo set, qual será as durações dos rounds, o seu prazo limite e as entregas parciais (backlog do set).

\subsection{Rounds}

Os rounds são as menores iterações do projeto, responsáveis pelas entregas parciais dentro de um set. Assim, o conjunto de rounds forma um set.

Os rounds podem possuir um tempo de duração flexível, de acordo com as entregas parciais a serem realizadas, que será definido na reunião de set. Entretanto, cada round deverá 
ter um tempo máximo de duração de quinze dias para que as iterações sejam curtas e as entregas parciais sejam validadas rapidamente. E ter a duração mínima de três dias, para evitar frustrações na equipe e garantir um tempo viável para cumprir as entregas parciais.

Outrossim, os tempos dos rounds devem ser acordados pela equipe e nunca determinados por um líder, contudo, essa duração deve ser orientada pelo prazo limite do set definido na reunião de set, para que as entregas sejam cumpridas sem extrapolar o planejamento.

\subsubsection{Reunião de corner}

As reuniões de corner acontecem durante os rounds e devem ter a participação de toda equipe. Neste encontro, os membros informam as atividades em andamento e discutem as melhorias que devem ser feitas a respeito das entregas parciais e dos processos internos.

Esta reunião deve ser realizada a cada três dias ou duas vezes na semana, em horários acordados na fase de planejamento tático. Isso ocorre para criar um senso de rotina na equipe, sendo possível que os membros organizem suas rotinas de trabalho com as práticas do projeto e garantam que os impedimentos internos do grupo sejam solucionados o mais rápido possível.

\subsection{Equipe}

A equipe deverá ter entre três a seis pessoas; deve ser multidisciplinar, com membros que possuam habilidades distintas e complementares, para que a construção do produto e as etapas de melhorias sejam mais enriquecedoras e abordem contextos diferentes, e para que seja viável a construção do produto dentro da equipe do início ao fim do projeto.

\subsubsection{Coach $e$ Vice-Coach}

O coach é único membro da equipe que não participa ativamente do desenvolvimento do produto. Ele é definido no planejamento tático e tem papel fundamental no gerenciamento do projeto.

Outrossim, é responsável por mediar as reuniões do projeto, coordenar a validação com o cliente, testar a viabilidade das melhorias propostas e trazê-las para serem discutidas nas reuniões de set, garantir que o planejamento dos rounds esteja conforme com os prazos do set e atualizar o plano tático. 
O coach funciona como facilitador para a equipe, se os membros tiverem dificuldades técnicas, burocráticas ou organizacionais, que possam afetar as entregas nos rounds, eles devem recorrer ao coach para auxiliá-los.

Para assumir essa função, é importante possuir algumas habilidades pessoais e técnicas desenvolvidas: perfil comunicativo; liderança; domínio técnico do modelo de gerenciamento de projetos.

Em caso de faltas, doenças ou desligamento do projeto, o vice-coach substituirá o coach. O primeiro é um membro da equipe que possui um papel no desenvolvimento do produto e deverá ter habilidades técnicas e pessoais desenvolvidas semelhantes ao coach.

\subsection{Fluxo da proposta de modelo}

O fluxo da proposta do modelo de gerenciamento de projetos para o desenvolvimento de novos produtos está na Figura 11.

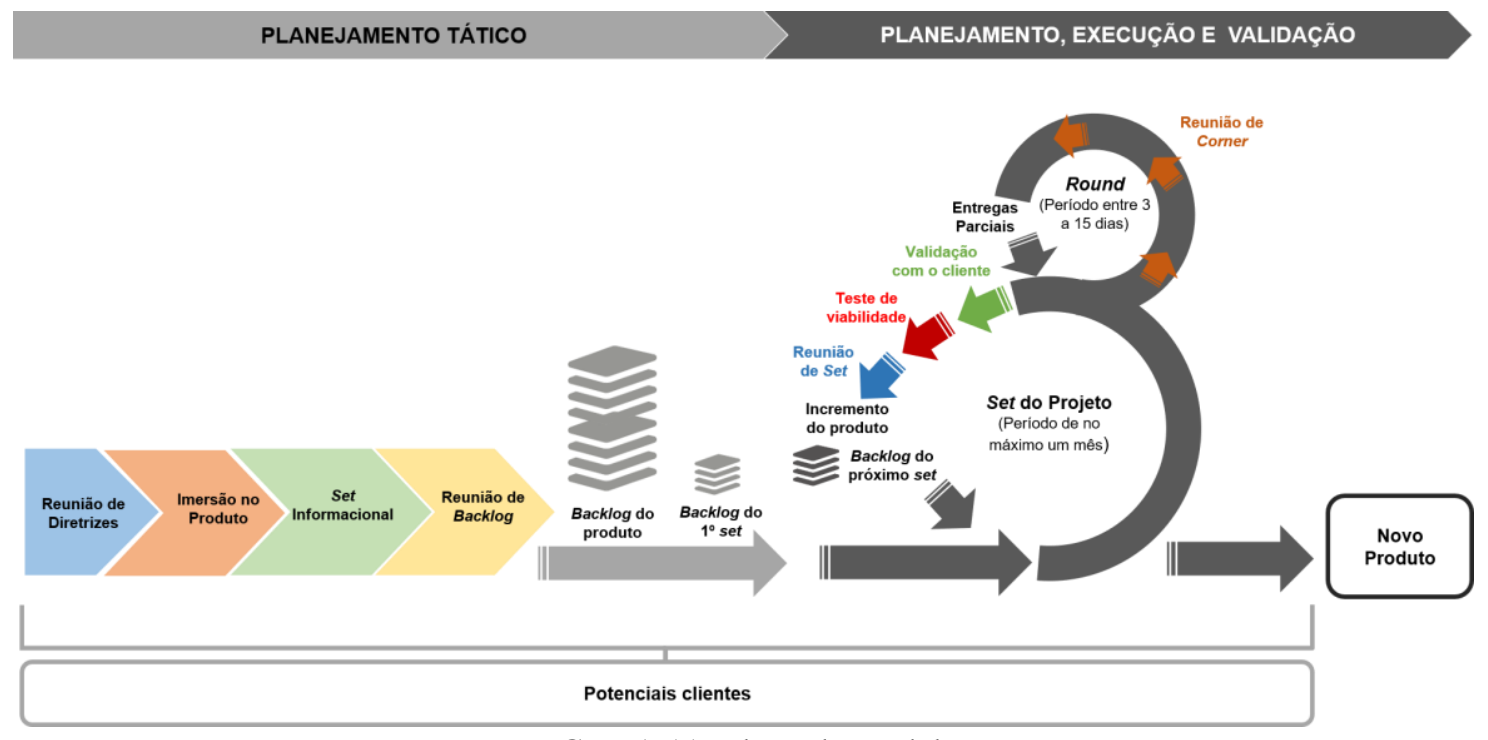

FIGURA 11- Fluxo do modelo

FONTE: Elaboração própria (2019).

\section{CONCLUSÃO}

Este artigo teve como objetivo geral propor um modelo de gerenciamento de projetos para desenvolvimento de novos produtos cuja particularidade é da natureza de uma disciplina do curso de graduação com as características de um projeto com restrições de tempo, recursos humanos e financeiros.

Considerando a questão que deu origem à pesquisa, conclui-se que um modelo que possa contribuir para o gerenciamento adequado no desenvolvimento de um novo produto 
deveria seguir uma abordagem híbrida de gerenciamento de projetos entre a tradicional, baseado no plano, e de resposta ágil, baseado nas características da flexibilidade e interação da equipe de desenvolvimento com os potenciais clientes.

A abordagem tradicional de gerenciamento de projetos tem seus pontos positivos e para a natureza do projeto tratado resulta útil na fase de planejamento tático do desenvolvimento do novo produto. Já a abordagem ágil possui características na fase dos sets do projeto.

Recomenda-se para trabalhos futuros a aplicação e adaptação da proposta de modelo de gerenciamento de projetos para desenvolvimento de produtos em outras organizações a partir de uma pesquisa de estudo de caso.

Também é recomendado um estudo referente aos índices de sucesso do uso do método proposto, trazendo as dificuldades e os benefícios de sua aplicação nas organizações e como reflete no desenvolvimento do produto.

\section{REFERÊNCIAS}

AMARAL, Daniel C.; CONFORTO, Edivandro C.. Métodos Ágeis para Gerenciamento de Projetos. In: JUGEND, Daniel; BARBALHO, Sanderson C. M.; SILVA, Ségio L. da. Gestão de Projetos: Teoria, Prática e Tendência. Rio de Janeiro: Elsevier, 2014. Cap. 5. p. 83-110.

BARBAlHO, Sanderson C. M.; CASTELlANI, Maria A.. Fundamentos do PMBOK. In: JUGEND, Daniel; BARBALHO, Sanderson C. M.; SILVA, Ségio L. da. Gestão de Projetos: Teoria, Prática e Tendência. Rio de Janeiro: Elsevier, 2014. Cap. 1. p. 1-25.

BIANCHI, Michael J. Ferramenta para configuração de modelos híbridos de gerenciamento de projetos. 2017. Dissertação (Mestrado em Engenharia de Produção) - Universidade de São Paulo, São Carlos, 2017.

BOEHM, Barry; TURNER, Richard. Using Risk to Balance Agile and Plan- Driven Methods. IEEE Computer Society, v. 36, n. 6, p.57-66, jun. 2003.

DEÁK, Csaba. Managing Innovation Projects versus Ordinary Project Management. In: Innovation Symposium: Stimulating Recovery - The Role of Innovation Management, 2, 2009, New York City. Anais... New York City, 2009.

EDER, Samuel et al. Diferenciando as abordagens tradicional e ágil de gerenciamento de projetos. Production, São Paulo, v. 25, n. 3, p.482-497, 18 abr. 2014.

GALEGO, Carla.; GOMES, Alberto. Emancipação, ruptura e inovação: o "focus group" como instrumento de investigação. Revista Lusófona de Educação, n.5, p. 173-184, 2005.

GONZÁLEZ, Mario Orestes A. Plano de Ensino: Laboratório de Engenharia do Produto. 2019

MORGAN, David. L. Focus groups as qualitative research. 2. ed. Beverly Hills: SAGE Publications, 1997.

PMI (Project Management Institute). A guide to the project management body of knowledge (PMBOK® guide). 6. ed. Newtown Square: Global Standard, 2017.

ROZENFELD, Henrique et al. Gestão de Desenvolvimento de Produtos: Uma Referência para a Melhoria do Processo. São Paulo: Saraiva, 2006.

SCHWABER, Ken; SUTHERLAND, Jeff. The Definitive Guide to Scrum: The Rules of the Game, 2017. 
11 a 13 de setembro de 2019 - Universidade de Brasília UnB

SILVA, Técia de L.. Gestão da Implantação de Projetos de Inovação em uma Organização Pública: Uma Proposta de Modelo. 2018. 95 f. TCC (Graduação) - Curso de Engenharia de Produção, Universidade Federal do Rio Grande do Norte, Natal, 2018.

UFRN (Universidade Federal do Rio Grande do Norte). Relatório de Gestão do Exercício de 2017. Natal, 2017. 